\title{
U sjeni Carpaccia: Scuola di San Giorgio degli Schiavoni u ranoj povijesnoumjetničkoj literaturi
}

Trška, Tanja

Source / Izvornik: Institucije povijesti umjetnosti : zbornik 4. kongresa hrvatskih povjesničara umjetnosti, 2019, 113 - 116

Conference paper / Rad u zborniku

Publication status / Verzija rada: Published version / Objavljena verzija rada (izdavačev PDF)

https://doi.org/10.31664/z4khpu.15

Permanent link / Trajna poveznica: https://urn.nsk.hr/urn:nbn:hr:254:303617

Rights / Prava: Attribution 4.0 International/Imenovanje 4.0 međunarodna

Download date / Datum preuzimanja: 2023-04-26

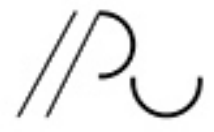

INSIIIUTZZA POVIJEST UMJETNOSI
Repository / Repozitorij:

PODEST - Institute of Art History Repository

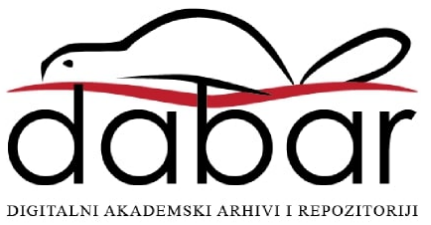




\section{U sjeni Carpaccia: Scuola di San Giorgio degli Schiavoni u ranoj povijesnoumjetničkoj literaturi}

U mnoštvu literature o znamenitostima grada kao što je Venecija, spomen sjedišta bratovštine iseljenika s istočne obale Jadrana povijesnoga imena Scuola dei SS. Giorgio e Trifone (Scuola di San Giorgio degli Schiavoni), a danas aktivne kao Scuola Dalmata dei SS. Giorgio e Trifone, nema uvijek iste razloge. ${ }^{1}$ Premda nije riječ o spomeniku koji biva izostavljen u pregledima venecijanske baštine, posebice onima topografskoga karaktera, broj redaka koji mu je posvećen i pristup autora pisanoga djela bitno je odredio ciklus slika Vittorea Carpaccia smješten u prizemlju sjedišta bratovštine, kojim je ona pronašla put do povijesnoumjetničke literature. No povjesničaru umjetnosti, ili povjesničaru kulture, Scuola di San Giorgio degli Schiavoni mnogo je više od mjesta na kojemu se nalazi Carpacciov narativni ciklus: devet slika venecijanskoga slikara čine tek nešto manje od petine slikarskih djela (od ukupno četrdeset i dva) nastalih u razdoblju od I5. do I8. stoljeća koja se danas nalaze u sjedištu bratovštine. Razumljivo, spomen nekoga djela u povijesnoumjetničkoj literaturi najčešće je rezultat njegove likovne kvalitete, a u onu Carpacciova ciklusa ni jedan pisac, očekivano, nije posumnjao.

Najraniji tiskom objavljeni podaci o Bratovštini sv. Jurja i Tripuna ograničeni su na pisce venecijanskoga podneblja. Prvi, premda usputni spomen bratovštine u tiskanoj literaturi o umjetnosti daje Francesco Sansovino u djelu Venezia città nobilissima prvi put objavljenu I58I. godine, gdje se autor pohvalno osvrće na arhitekturu nedavno izgrađena sjedišta bratovštine koji su stari pisci pripisivali njegovu ocu Jacopu Sansovinu. ${ }^{2}$ Francesco Sansovino ne spominje Carpacciov ciklus; na njega će se u kasnijem izdanju tiskanu više od osamdeset godina poslije kratko osvrnuti Giustiniano Martinioni u dodatku izvornom Sansovinovu tekstu, ali bez spomena drugih umjetničkih djela koja su već tada krasila sjedište bratovštine. ${ }^{3}$ Više zanimanja za unutrašnjost Scuole di San Giorgio degli Schiavoni pokazat će pisci baroknoga razdoblja, počevši od

\section{Tanja Trška}

Odsjek za povijest umjetnosti Filozofski fakultet Sveučilište u Zagrebu ttrska@ffzg.hr

https://orcid.org/oooo-ooo2-o83I-I730
I O povijesti bratovštine usp. osobito istraživanja Lovorke Čoralić, sabrana u: LOVORKA ČORALIĆ, Hrvatski prinosi mletačkoj kulturi: odabrane teme, Zagreb, Dom i svijet, 2003., I59-2I0; ISTA, U gradu svetoga Marka. Povijest hrvatske zajednice u Mlecima, Zagreb, Golden marketing, 20OI., 2I5-262, sa starijom literaturom. O umjetničkoj baštini bratovštine usp. Le Scuole di Venezia, (ur.) Terisio Pignatti, Milano, Electa, I984., 99-ı18, s relevantnom literaturom.

2 „Vicino al detto è l'Oratorio della natione Schiavona sotto titolo di San Giorgio, con ricca \& bene intesa struttura fatta pochi anni sono. Era già Spedale sotto titolo di Santa Caterina, \& lo possedeva il predetto Priorato di Sau [sic] Giovanni." FRANCESCO SANSOVINO, Venetia citta nobilissima et singolare, Venezia, Appresso Iacopo Sansovino, I58I., I3v. Jacopa Sansovina kao autora projekta za obnovljeno pročelje bratovštine spominju: ERMOLAO PAOLETTI, Il fiore di Venezia ossia i quadri, i monumenti, le vedute ed i costumi veneziani, sv. 2, Venezia, Tommaso Fontana, I839., 207; ANTONIO QUADRI, Descrizione topografica di Venezia e delle adjacenti lagune, Venezia, Gio. Cecchini, I844., 83; PIETRo sElvATICO, Sulla architettura e sulla scultura in Venezia dal Medio Evo sino ai nostri giorni, Venezia, Paolo Ripamonti Carpano, I847., 298-299.

3 ,[...] l'Oratorio quivi vicino, nel quale Vittor Carpaccio dipinse alcune attioni delli medesimi Santi Giorgio, Trifone e Girolamo, con due Historie Evangeliche." FRANCESCO SANSOVINO, Venetia citta nobilissima et singolare, (ur.) Giustiniano Martinioni, Venezia, Appresso Steffano Curti, I663., 47. Tom je izdanju prethodilo ono iz I6o4. godine koje je uredio Giovanni Stringa (Venezia, Presso Altobello Salicato, I6o4., I37), u kojem je u odnosu na Sansovinov tekst o bratovštini dodan samo prijepis natpisa na pročelju datiran I55I. godinom. 
Carla Ridolfija, koji u životopisu Vittorea Carpaccia u djelu Le Maraviglie dell'arte iz I648. godine opisuje narativni ciklus u bratovštini, posebno prizore posvećene sv. Jurju, ${ }^{4}$ zatim Marca Boschinija, koji u djelu Le miniere di pittura tiskanom I664. godine (kao i u neizmijenjenu tekstu drugoga izdanja iz I674. godine) ističe Carpacciove opere preziose i uvodi dva djela čiji je autor slikar grčkoga podrijetla Antonio Vassilacchi zvan l'Aliense (Milos, I556.-Venecija, I629.). ${ }^{5}$ Sansovinove i Boschinijeve podatke spojio je Domenico Martinelli I684. godine, ${ }^{6}$ a Zanettijeva „obnova” Boschinijeva djela Le ricche miniere iz I733. ne nudi ništa više od svoga predloška, ${ }^{7}$ kao ni Forestiere illuminato Giambattiste Albrizzija objavljen I740. godine, $\mathrm{u}$ kojem se također ističu preziose pitture Vittorea Carpaccia. ${ }^{8}$ Pristup spomenutih pisaca baroknoga razdoblja razlikuje se, razumljivo, ovisno o prirodi djela: Ridolfijev se opis temelji na Vasarijevu modelu životopisa u kojemu se nastoji dati što potpunija informacija o opusu pojedinog slikara, dok su ostali pisci preuzeli Sansovinov model vodiča po crkvama i spomenicima, s bitnom razlikom da je u odnosu na Sansovinovo djelo i njegova kasnija izdanja, gdje se Scuola navodi u okviru priorata Malteških vitezova pri crkvi San Giovanni del Tempio, sjedištu bratovštine posvećena zasebno naslovljena cjelina, počevši od prvog izdanja Boschinijeva djela Le minere della pittura..$^{9}$ Neovisno o tome, ime koje pronosi bratovštinu Schiavona u ranim tekstovima uvijek je Vittore Carpaccio, a ostala se djela i ne spominju. ${ }^{10}$ Naime, sudeći prema stavu Antona Marije Zanettija iznesenu u djelu Della pittura veneziana objavljenu I77I. godine, osim radi Carpaccia nema razloga "ondje dulje zadržati ljubitelja umjetnosti". ${ }^{11}$ Tako je u Carpacciovoj sjeni-ili, ako promijenimo kut gledanja, na krilima njegovih telera-Scuola di San Giorgio degli Schiavoni dočekala ig. stoljeće.

Tek se tada pogled i pero pisaca o umjetnosti uspinje prema gore, u takozvanu salu superiore, uređenu u posljednjim desetljećima I6. i prvim desetljećima I7. stoljeća, s oslikanim kasetiranim drvenim stropom i nizom slika po narudžbi vodećih članova bratovštine toga razdoblja. U nizu sve brojnijih djela posvećenih venecijanskoj likovnoj baštini napisanih tijekom I9. stoljeća-opisa i vodiča organiziranih po topografskom ključu te pregleda venecijanske umjetnosti i umjetnika vođenih kvalitativnim kriterijima-prvi je zadatak razlučiti koja su ona koja pripadaju kategoriji pisanja povijesti umjetnosti. Pritom se kao pouzdan vodič nameće Die Kunstliteratur Juliusa von Schlossera, koji među izdanjima o venecijanskoj umjetnosti Ig. stoljeća visoko postavlja djelo Giannantonija Moschinija Guida per la città di Venezia all'amico delle belle arti objavljeno I8I5. godine, smatrajući ga najranijim djelom koje doista predstavlja cjelokupnu venecijansku umjetnost. ${ }^{12}$ Sveobuhvatnost koju ističe von Schlosser ogleda se i u opisu Scuole di San Giorgio degli Schiavoni, kojoj je Moschini posvetio gotovo četiri stranice teksta, a nakon iscrpna opisa telera Carpacciova ciklusa doista se uspeo na kat sjedišta bratovštine i dao prvi opis djela koja se tamo nalaze. ${ }^{13}$ Unatoč ponešto obeshrabrujućem početku-stubište prekriveno „tužnim” djelima
4 „Le furono allogate ancora da' fratelli della Cõmpagnia di S. Giorgio tre historie di braccia, due in circa di altezza, nelle due prime fece il Santo Cavaliere, che uccide il Drago, che infettava la Città di Berito, liberandone la figliuola del Rè; e come viene incontrato dal Rè, e dalla Regina, e dal Popolo con canti, e suoni, mentre conduce il Drago ucciso alla Città, \& un Valletto gli tiene il destriere, ammirandolo dalle fenestre decorate Matrone; e nella terza il Rè, e la Regina vengono battezzati dal Santo, e dietro han servi, che tengono il diadema, aurei vasi, \& manti Reali. Segui anco à dipingere nel giro un'historia di San Trifone, due dell'Evangelo, e tre di San Girolamo." CARLO RIDOLFI, Le maraviglie dell'arte, ovvero le vite degli illustri pittori veneti e dello Stato, Venezia, Presso Gio: Battista Sgava, I648., 30.

5 „Vi sono nove quadri di Vittore Carpaccio, alcuni contengono la vita, e miracoli di S. Giorgio, \& altri la vita, e miracoli di S. Girolamo, \& in uno nostro Signore all'Horto, opere preziose, fatte dal M.D.II. fino al M.D.VII. Vi è anco Christo, che risorge dell'Aliense. Evvi poi il Confalone, che il giorno della festività si mette fuori della Scuola, sopra il quale si vede il Santo Cavaliere, che uccide il Drago, e li Santi Simeone, Trifone, e Girolamo, con molti bellissimi ornamenti; opera di Antonio Aliense." MARCO BOSCHINI, Le minere della pittura, Venezia, Appresso Francesco Nicolini, I664., I94; ISTI, Le ricche minere della pittura veneziana. Seconda Impressione con nove aggiunte, Venezia, Appresso Francesco Nicolini, I674., 37 (Sestiere di Castello).

6 DOMENICO MARTINELLI, Il ritratto di Venezia diviso in due parti, Venezia, Presso Gio: Giacomo Hertz, I684., 208.

7 [ANTONIO MARIA ZANETTI,] Descrizione di tutte le pubbliche pitture della città di Venezia e Isole circonvicine: O sia Rinnovazione delle Ricche Minere di Marco Boschini, Colla aggiunta di tutte le opere, che uscirono dal I674. fino al presente I733. con un compendio delle vite, e maniere de' principali pittori, Venezia, Presso Pietro Bassaglia, I733., 229.

8 GiAmBATtista ALBRIZZI, Forestiere illuminato intorno le cose piu rare e curiose, antiche, e moderne della citta di Venezia e dell'Isole circonvicine, Venezia, presso Giambatista Albrizzi q. Gir., I740., I2I.

9 Premda je riječ o djelu povijesnog, a ne povijesnoumjetničkog karaktera, iznimka je FLAMINIO CORNER, Notizie storiche delle chiese e monasteri di Venezia, e di Torcello, tratte dalle chiese veneziane, e torcellane, Padova, Nella stamperia del Seminario appresso G. Manfrè, I758., I67-I68, gdje su podaci o Scuoli di San Giorgio e Trifone uključeni u poglavlje o crkvi sv. Ivana Krstitelja Malteških vitezova.

Io PIETRO A. PACIFICO, Cronaca veneta sacra e profana osia compendio di tutte le cose più illustri ed antiche della città di Venezia, Venezia, Pitteri, I75I., 200: „Nell'Oratorio de' Schiavoni, ch' è posto fuori vi lavorò Vittorio Carpaccio."

II „Niente più farò trattener quivi l'Amator di Pittura." ANTON MARIA ZANETTI, Della pittura veneziana e delle opere pubbliche de' veneziani maestri libri V, Venezia, Nella stamperia di Giambatista Albrizzi, I77I., 37 .

I2 JULIUS VON SCHLOSSER, Die Kunstliteratur: ein Handbuch zur Quellenkunde der neueren Kunstgeschichte, Wien, Schroll, I924., 487.

I3 GiAnNANTONio MOschini, Guida per la città di Venezia all'amico delle belle arti, sv. I, Venezia, Nella tipografia di Alvisopoli, I8I5., 92-93. 
te pokojim osrednjim ${ }^{14}-\mathrm{u}$ opisu slika uz Carpaccia javljaju se druga imena: l'Aliense u prizemlju i način Palme Mlađega i Jacopa Tintoretta na katu. Bez obzira na lapidarna atributivna određenja opisanih djela koja tek nagoviještaju vrijeme nastanka slika i neke opće uzore, Moschinijev pogled u salu superiore potaknuo je i kasnije autore da se osvrnu na njezino uređenje, premda nerijetko s negativnom ocjenom. ${ }^{15} \mathrm{U}$ vodiču Pietra Selvatica i Vincenza Lazarija iz I852. godine tako su na katu spomenuta „ružna platna” Tintorettove i Palmine škole, ${ }^{16}$ što su u kasnijem izdanju objavljenu i88I. ublažili Rinaldo Fulin i Pompeo Molmenti ocijenivši ih „osrednjima”. ${ }^{17}$ Premda usmjereni ponajprije na Carpaccia, za ostala djela u sjedištu bratovštine vodiči I9. stoljeća poput spomenutoga djela Pietra Selvatica i Vicenza Lazarija ipak dobivaju karakter povijesnoumjetničkih izvora, posebice s obzirom na restauratorske zahvate Ig. stoljeća i privremena ili trajna izmještanja umjetnina. ${ }^{18}$

Niz vodiča Ig. stoljeća koje von Schlosser ocjenjuje „napisanima za užurbane strance bez povijesnoumjetničkih namjera"19 ponavlja iste obrasce i ističe Carpaccia kao glavnu atrakciju bratovštine, a njihovi pisci kao da su se ulaskom u Scuolu di San Giorgio degli Schiavoni ogrnuli renesansnim kostimima Carpacciova vremena koje je svojim Kritičarima i894. godine duhovito odjenuo američki slikar Joseph Lindon Smith (Pawtucket, Rhode Island, I863.-Dublin, New Hampshire, I950.). ${ }^{20} \mathrm{U}$ istome je razdoblju prisutan i hrvatski, odnosno slavenski pogled na bratovštinu, prije svega na Carpaccia, sadržan u nezaobilaznom Slouniku Ivana Kukuljevića Sakcinskog (I858.). Za slike u „hrvatskoj kapeli sv. Jurja” Kukuljević smatra da su ih „mletački Hrvati načinili po svom sunarodniku Karpatu”, za koje je „znamenito [...] da se na ovih krasnih slikah, što ih je troškom Hrvatah radio, nigdje nije podpisao kao Mlečanin (Venetus)", te da toliki broj slikarevih djela u toj kapeli navodi na pomisao „da ju je Karpat iz njeke prirodjene privrženosti i dužnosti nakititi htjeo". ${ }^{21}$ Kukuljevićevo isticanje Carpacciovih djela u bratovštini Schiavona ima, naravno, sasvim druge ciljeve $u$ odnosu na djela talijanskih pisaca istoga ili ranijih razdoblja, pri čemu, kako je ocijenila Ivana Mance, „Kukuljević projicira ideološki koncept nacionalizma u povijesno vrijeme za koje je on irelevantan". ${ }^{22}$

Namjera ovog kratkog pregleda zastupljenosti Scuole di San Giorgio degli Schiavoni u odabranim djelima rane povijesnoumjetničke literature jest istaknuti potrebu cjelovitog pristupa likovnoj baštini bratovštine koju su hrvatska historiografija i povijest umjetnosti I9. i 20. stoljeća često odlučivale zvati „svojom”. Bez obzira na njihovu sasvim opravdano slabiju valorizaciju u odnosu na Carpacciova djela, kao i u kontekstu venecijanske umjetničke produkcije i6. i i7. stoljeća koja je visoko postavila vrijednosnu ljestvicu, nerijetko prešućivana djela na katu bratovštine Schiavona odraz su različitih načina prikazivanja kolektivne i individualne prošlosti kojima su njezini članovi nastojali definirati svoj položaj u venecijanskom društvu. Umjesto zaključka vrijedi ponoviti misao koju je u prilogu naslovljenu Što sve jest, a što nije umjetnička baština
I4 „Ascendendo la scala, tutta coperta di opere e tristi, e alcuna mediocre sullo stile di Palma”. GIANNANTONIO MOSCHINI (bilj. I3), 92.

I5 „A lato dell'altare evvi la scala che mena al piano superiore per le capitolari riduzioni della confraternita. Parecchi dipinti adornano quella sala, ma niuno vuol essere punto osservato." ERMOLAO PAOLETTI (bilj. 2), 207.

I6 „[...] brutte tele della scuola del Tintoretto e del Palma Giovane." PIETRO SELVATICO, VINCENZO LAZARI, Guida di Venezia e delle isole circonvicine, Venezia, Carlo Bianchi, Ripamonti Carpano, I852., Ior. Srodnu ocjenu donosi i vodič Una settimana a Venezia. Guida illustrata per visitare quanto vi ha di più degno di considerazione nella città e sue isole, Venezia, Trieste, Milano, Colombo Coen Editore, I873. [4. izdanje], 9ı: „meschine tele della scuola del Tintoretto e del Palma il giovine."

I7 „[... mediocri tele delle scuole del Tintoretto e di Palma il Giovane." PIETRo SELVATICO, VINCENZO LAZARI, Guida di Venezia e delle isole circonvicine, (ur.) Rinaldo Fulin, Pompeo Gherardo Molmenti, Venezia, Tipografia di G. Antonelli, I88I., I88.

I8 Selvatico i Lazari u izdanju iz I852. godine spominju oltarnu palu Bogorodice s Djetetom između sv. Jeronima i sv. Tripuna, koja je „nedavno zamijenjena" palom Bogorodice s Djetetom na prijestolju koju navode kao djelo Vicenza Catene (još na oltaru u prizemlju sjedišta bratovštine). Bočna polja s prikazima sv. Jeronima i sv. Tripuna odgovaraju slikanim poljima danas na gornjem katu bratovštine, koja su vjerojatno dijelovi prvoga poliptiha naručena za oltar bratovštine u crkvi San Giovanni del Tempio nedugo nakon njezina osnutka I45I. godine. Usp. Le Scuole di Venezia (bilj. I), II8.

I9 JULIUS VON SCHLOSSER (bilj. I2), 498.

20 Kritičari: San Giorgio degli Schiavoni, Venecija, I894., akvarel, 76,2 × Iı6,2 cm. Boston, Museum of Fine Arts. Joseph Lindon Smith jedan je od niza američkih slikara koji su potkraj I9. i početkom 2o. stoljeća nastojali oživiti sjaj venecijanske prošlosti. Usp. MARGARETTA M. LOVELL, A visitable past: views of Venice by American artists, I86o-I9I5, Chicago, The University of Chicago Press, I989., II.

2I IVAN KUKULJEVIĆ SAKCINSKI, Slovnik umjetnikah jugoslavenskih, Zagreb, Tiskom Narodne tiskarne Dra. Ljudevita Gaja, I858., I40-I4I.

22 IVANA MANCE, Zercalo naroda. Ivan Kukuljević Sakcinski: povijest umjetnosti i politika, Zagreb, Institut za povijest umjetnosti, 20I2., 242 
iznio Dino Milinović na II. kongresu povjesničara umjetnosti, želeći „upozoriti na to da su povjesničari umjetnosti ti koji kreiraju pojam umjetničke baštine, odnosno da 'umjetnička baština' postoji u onoj mjeri u kojoj povjesničari umjetnosti prepoznaju i uspijevaju valorizirati djela koja ju sačinjavaju."23

Ovaj rad nastao je u okviru projekta Hrvatske zaklade za znanost br. 2305-Vizualiziranje nacionalnoga: umjetnost $i$ arhitektura bratovština i kolegija Schiavona/Ilira u Italiji i razmjena umjetničkih iskustava s jugoistočnom Europom od I5. do I8. st.
23 DINO MILINOVIĆ, Što sve jest, a što nije umjetnička baština: nedovršeni posao hrvatskih povjesničara umjetnosti, u: Zbornik II. kongresa hrvatskih povjesničara umjetnosti (Zagreb, 27.-29. travnja 2006.), (ur.) Irena Kraševac, Zagreb, Institut za povijest umjetnosti, 2007., 27.

\section{(c) (i)}

U sjeni Carpaccia: Scuola di San Giorgio degli Schiavoni u ranoj

povijesnoumjetničkoj literaturi / Tanja Trška / CC BY / 4.0

DOI: https://doi.org/Io.3I664/z4khpu.I5

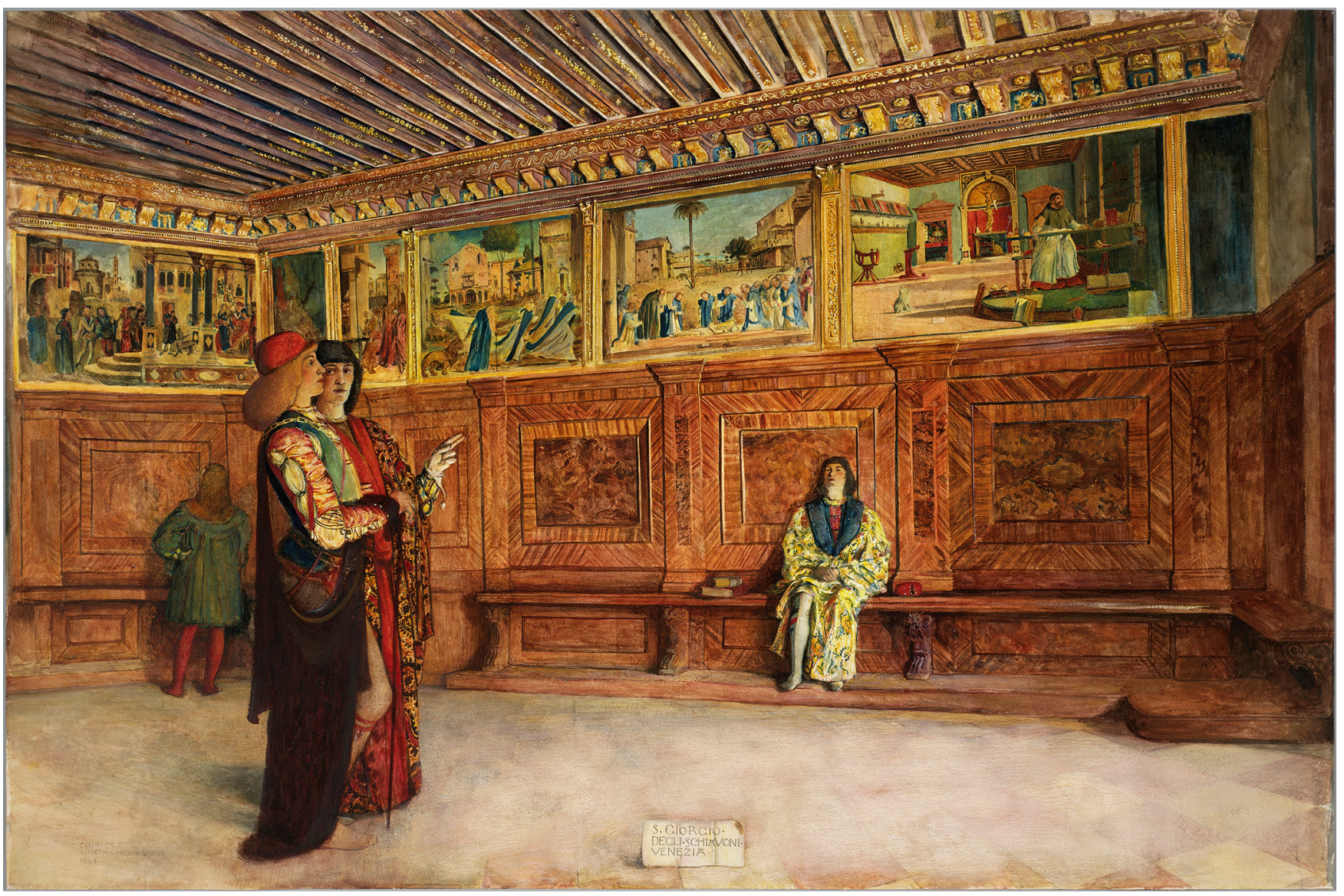

Joseph Lindon Smith, Kritičari: San Giorgio degli Schiavoni, Venecija, 1894. akvarel, $76,2 \times$ II $6,2 \mathrm{~cm}$, Boston, Museum of Fine Arts,

foto: () 20I9 Museum of Fine Arts, Boston 